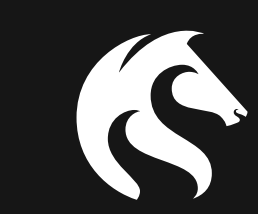

THE UNIVERSITY OF NEWCASTLE AUSTRALIA

\title{
PROFESSIONAL STANDARDS FOR
}

\section{AUSTRALIAN SPECIAL EDUCATION TEACHERS}

If you're an Australian Special Education teacher, please give us your views on the extent to which a set of draft statements describing the essential work of special education teachers apply to you. This research is being conducted by Associate Professor lan Dempsey and Dr. Kerry Dally from the University of Newcastle.

If you'd like more information about this research, please follow the link below and, if after reading the Information Statement you agree to participate, you can complete the questionnaire online.

newcastle.edu.au/survey0066

Kind regards, Ian Dempsey and Kerry Dally 


\section{Announcement}

15th World Congress of the International Association for the Scientific Study of Intellectual and Developmental Disabilities

Melbourne Conference and Exhibition Centre 15-19 August, 2016 - Melbourne, Vic. Australia

\section{Highlights and Key Events}

24 Keynote Addresses and Master Lectures

Past Presidents' Forum

Platform Presentations and Symposia

Poster Sessions and Poster Symposia

Exhibits and Video Theatre

Pre-Congress IASSIDD Academy Workshops

Pre-Congress Support Workers' Conference

Social Program - Networking and Exchanges

Travel scholarships available for scientists, students, and self-advocates

\section{Key Dates:}

Abstract Submissions: 1 September through 15 December 2015

Registration and Accommodations Open: 1 September 2015

For information: www. IASSIDD.org

Visit IASSIDD World Congress Facebook and Twitter Pages for Regular Updates 


\section{Children Australia}

Published for The Australian Association of Special Education Inc.

\section{Editor}

Jennifer Lehmann, La Trobe University, Australia

Children Australia links policy, research and practice issues on matters associated with children, young people and family wellbeing. It challenges some of the traditional ideas, practices and 'silos' associated with professional disciplines, roles and activities. The journal provides an opportunity for professional staff, academics and others concerned with children, youth and families, to report on a wide range of topics that address Australian and international ideas and developments. It is highly relevant to a wide readership, including academics, administrators, teachers, students and all professionals working in human services fields. Debate and discussion is encouraged as a means to explore and develop the myriad practices contributing to the well-being for children, young people and their families.

\section{Price information}

is available at: http://journals.cambridge.org/cha

\section{Free email alerts}

Keep up-to-date with new material - sign up at http://journals.cambridge.org/alerts

To subscribe contact Customer Services

\section{in Cambridge:}

Phone $+44(0) 1223326070$

$\mathrm{Fax}+44(0) 1223325150$

Email journals@cambridge.org

in New York:

Phone +1 (845) 3537500

Fax +1 (845) 3534141

Email

subscriptions_newyork@cambridge.org 


\section{Journal of Child Language}

\section{Editors}

Heike Behrens, University of Basel, Switzerland Johanne Paradis, University of Alberta, Canada

A key publication in the field, Journal of Child Language publishes articles on all aspects of the scientific study of language development and behaviour in children, the principles which underlie it, and the theories which may account for it. The international range of authors and breadth of coverage allow the journal to forge links between many different areas of research including psychology, linguistics, cognitive science, speech pathology and anthropology. The interdisciplinary and crosslinguistic perspective spans a wide range of interests: phonology, phonetics, morphology, syntax, vocabulary, semantics, pragmatics, sociolinguistics and other recognised aspects of language study. In addition to articles and brief research reports, the journal also features occasional review articles plus invited commentaries.

\section{Price information}

is available at: http://journals.cambridge.org/jcl

\section{Free email alerts}

Keep up-to-date with new material - sign up at http://journals.cambridge.org/alerts

Journal of Child Language

is available online at:

http://journals.cambridge.org/jcl

To subscribe contact

Customer Services

Americas:

Phone +1 (845) 3537500

Fax +1 (845) 3534141

Email

subscriptions_newyork@cambridge.org

\section{Rest of world:}

Phone +44 (0)1223 326070

$\mathrm{Fax}+44(0) 1223325150$

Email journals@cambridge.org 


\section{SUBMISSION}

Australasian Journal of Special Education (AJSE) accepts submissions through ScholarOne for online submission and peer review. To be reviewed for possible publication in this journal, authors must follow the instructions below. New users first need to create an account. Once logged on, submission must be made through the 'Author Centre.' At least two separate files need to be submitted online via https://mc.manuscriptcentral.com/ajse

Authors must submit

- a Title Page. This should include (a) article title; (b) name, credentials, affiliation, address, telephone number(s), and email address of the corresponding author; (c) the names, credentials, and affiliations of all authors; (d) any acknowledgements, financial disclosure information, including conflicts of interest statements, author notes, and/or other text that could identify the authors to reviewers; and (e) that this manuscript is an original work that has not been submitted to or published anywhere else. A word count and suggested running header of no more than 50 character including spaces should also be provided, along with a maximum of 6 keywords. This document is separate from the article and not shared with the reviewers.

- the article document (Main Document). This document must be blinded and include an abstract not exceeding 200 words that provides a brief overview of the aims, method, and major findings.

2. Review. AJSE uses a double-blind review process. Manuscripts are initially assigned to the Editor and screened. If considered suitable for peer review, the manuscript is blind peer reviewed by at least two expert reviewers. The review process generally takes 3 to 4 months, not including any times of revision by the author. When reviews are returned, the Editor considers reviewers' comments, independently evaluates the manuscript, and makes an editorial decision to reject, request a revision with further peer review, request a revision subject to review by the Editor, or accept as is. Authors receive copies of (anonymous) reviewers comments. Although feedback will usually be provided to authors, the Editor reserves the right to reject a manuscript for publication without providing a rationale for the decision. Final decisions regarding acceptance of a manuscript will be made by the Editor.

3. Publishing Ethics. AJSE considers all manuscripts on the strict condition that

- the manuscript is your own original work, and does not duplicate any other previously published work, including your own previously published work

- the manuscript has been submitted only to the journal - it is not under consideration or peer review or accepted for publication or in press or published elsewhere;

- all listed authors know of and agree to the manuscript being submitted to the journal; and

- the manuscript contains nothing that is abusive, defamatory, fraudulent, illegal, libellous, or obscene.

By submitting your paper to AJSE you are agreeing to any necessary originality checks your paper may have to undergo during the peer review and production processes. The Editor will collaborate with Cambridge University Press using the guidelines of the Committee on Publication Ethics in cases of allegations of research errors, authorship complaints, multiple or simultaneous submission, plagiarism complaints, research results misappropriation, reviewer bias, and undisclosec conflicts of interest.

4. Authorship. All persons who have a reasonable claim to authorship must be named in the manuscript as co-authors; the corresponding author must be authorised by all co-authors to act on their behalf in all matter pertaining to publication of the manuscript, and the order of names should be agreed by all authors. Each author should have participated sufficiently in the work to take public responsibility for appropriate portions of the content. Authorship credit should be based on

- substantial contributions to conception and design, acquisition of data, or analysis and interpretation of data;

- drafting the article or revising it critically for important intellectual content; and

- final approval of the version to be published.

Authors should meet all conditions. Acquisition of funding, collection of data, or general supervision of the research group alone does no constitute authorship.

5. Manuscript Format and Style. All manuscripts must be in English. Contributions should follow the format and style described in the Publication Manual of the American Psychological Association (6th ed.). Spelling and punctuation should conform to The Macquarie Dictionary (6th ed). For matters of style not covered in these two publications, the Style Manual for Authors, Editors and Printers (6th ed.) should be consulted.

- The preferred length for research articles and literature reviews is no more than 7,000 words, including abstract, references, tables, and figures. The Editor may, at their discretion, accept papers that exceed this length where it is clear that the complexity and importance of the content warrants a longer paper. In such cases, authors should provide a rationale for a lengthier contribution upon submission.

- The Title Page and Main Document should be saved as Microsoft Word documents, double-spaced with minimum margins of $25 \mathrm{~mm}$ on all sides and in A4 page size. Times New Roman 12 pt size typeface is preferred.

- Authors should avoid language that can be seen as discriminating against people on account of disability, race, or gender.
- Use single quotation marks, except where 'a quotation is "within" a quotation, to introduce a word or phrase used as an ironic comment, as slang, or as an invented or coined expression. Use quotation marks the first time the word or phrase is used; do not use them again. Do not use quotation marks to introduce a technical or key term; italicise the term instead. Long quotations of 40 words or more should be formatted as a block quotation and italicised.

- Do not use any footnotes. Endnotes should be kept to a minimum and listed at the end of the text under the heading 'Notes'

6. Tables and Figures. Both tables and figures should be titled with a short concise description, numbered separately but consecutively, and referenced at least once in text. Tables and figures should be kept to a minimum.

7. Tables should be placed at the end of the manuscript, not in the main text. Their approximate positions in the text should be indicated by the words, 'Please insert Table X about here'. Horizontal and vertical lines should be used sparingly.

8. Figures, graphs, illustrations and photographs (not tables) should be prepared to the correct size and each one supplied as an individual file, separate to the manuscript file. Include placement instructions in the manuscript, such as 'Please insert Figure X about here'

- Figures created in Microsoft Word, Excel, or PowerPoint need to be saved as PDFs.

- Figures created in a drawing program should be saved as EPS (encapsulated postscript) files.

- Figures created in Photoshop or other photographic software should be saved with a minimum resolution of 600 dpi and in TIFF format. Minimum resolution for scanned graphics is $300 \mathrm{dpi}$ for halftone work (e.g. photographs) and $600 \mathrm{dpi}$ for line art, and these should also be in TIFF format. All figures and graphs should be in black and white line art (artwork that has only text and lines, no shades of grey or blocks of colour).

- All photographs should be supplied as separate files in JPEG or TIFF formats with a minimum 300 dpi resolution. (As a rough guide, the file size of each photograph should be above 200KB).

- Prior to submitting artwork, the separate figure files should be printed by the author to test that the fonts have been embedded correctly and there is no distortion in the artwork (e.g., lines and fonts reproduce cleanly with no jagged lines or fuzzy edges), as any such faults cannot be corrected by the publisher.

- A list of figure captions should follow the tables in the manuscript document.

9. Acknowledgements. Acknowledge individuals or organisations who provided advice or non-financial support. If there are no acknowledgements, include the heading 'Acknowledgements' followed by 'None'.

10. Financial Support. Provide details of the sources of financial and in-kind support for all authors, including grant numbers. Grants held by different authors should be identified as belonging to individual authors by the author's initials. Where no specific funding has been provided for research, please provide the following statement: 'This research received no specific grant from any funding agency, commercial, or not-for-profit sectors.'

11. Conflicts of Interest. Conflict of interest exists when an author has interests that might influence his or her judgement, even if that judgement is not influenced. Authors must disclose potential financial and any relevant non-financial conflicts of interest. This requirement applies to all authors named on a paper and to all categories of papers. If there are no conflicts of interest, include the heading 'Conflicts of Interest' followed by 'None'.

12. References and citations must be accurate and complete on submission and should follow the format and style described in the Publication Manual of the American Psychological Association (6th ed.). Papers will be declined for publication if they have references that are found to be incomplete or inaccurate. References should be selective, appropriate, and easily accessible. Examples of citations are:

The theory was first propounded in 1970 (Larsen, 1971). Larsen (1971) was the first to propound the theory.

Examples of references are:

Heward, W. L. (2006). Exceptional children: An introduction to special education (8th ed.). Upper Saddle River, NJ: Pearson.

Thomas, T. (2009). The age and qualifications of special education staff in Australia. Australasian Journal of Special Education, 33, 109116. doi:10.1375/ajse.33.2.109

13. Permissions. The corresponding author is responsible for providing copies of permissions obtained for lengthy quotations or reprinted or adapted tables or figures. It is the responsibility of the author to check with the publisher or copyright owner regarding specific requirements for permission to adapt or quote from copyrighted material. Appropriate acknowledgement of the source must be given in your manuscript.

14. Minor amendments may be made by editorial staff following review to ensure that reasonable standards of content, presentation, and readability are maintained.

15. The Australian Association of Special Education Inc. does not hold itself responsible for statements made by contributors.

16. Copyright. To assure the integrity, dissemination, and protection against copyright infringement of published articles, you will be asked to assign us, via a Publishing Agreement, the copyright in your article. Under the conditions detailed on the Journal's standard transfer of copyright form, when an article is accepted, its authors are free to post their version of the accepted manuscript on a website or repository. 


\section{Volume 39 | Issue 2 | December 2015}

\section{Contents}

\section{Articles}

Teacher Perceptions of Factors for Successful 97 Inclusive Early Childhood Education in

Hong Kong

Frances Lai Mui Lee, Alexander Seeshing Yeung, Katrina Barker, Danielle Tracey

and Jesmond C. M. Fan

Parent Perspectives on Sources of 113 Information About Autism Spectrum Disorder Interventions in Australia

Sarah Carlon, Jennifer Stephenson and Mark Carter
Asperger's and Girls: What Teachers Need 128 to Know

Belinda Jarman and Christopher Rayner

Insights Into the Support Services 